\title{
PROPRIEDADE FÍSICO-QUÍMICA DA PRÓPOLIS EM FUNÇÃO DA SAZONALIDADE E MÉTODO DE PRODUÇÃO
}

\author{
PHYSICOCHEMICAL PROPERTIES OF PROPOLIS IN FUNCTION OF SEASONALITY \\ AND PRODUCTION METHOD
}

Souza, E.A. ${ }^{1}$, Inoue, H.T. ${ }^{1}$, Gomes, S.M.A. ${ }^{1}$, Funari, S.R.C. ${ }^{1}$ e Orsi, R.O. ${ }^{1 *}$

${ }^{1}$ Departamento de Produção Animal. Faculdade de Medicina Veterinária e Zootecnia. UNESP. Campus de Botucatu. Botucatu. Distrito de Rubião Júnior, s/n. CEP 18618-000. São Paulo. Brasil. *orsi@fca.unesp.br

\section{PalaVRas chaVe ADICIONAIS}

Apis mellifera. Abelhas africanizadas.

\section{RESUMO}

O objetivo do presente trabalho foi avaliar o efeito da sazonalidade sobre algumas características físico-químicas (extrato seco, flavonóides totais, $\mathrm{pH}$ e atividade de oxidação) dos extratos alcoólicos (EAP) da própolis obtida mensalmente, durante um ano, por diferentes técnicas (coletor de própolis inteligente, tela plástica e raspagem) em quinze colméias de abelhas Apis mellifera africanizadas. Não foram observadas diferenças significativas $(p>0,05)$ nas análises físico-químicas dos EAP, em função da sazonalidade e técnica de produção.

\section{SUMMARY}

The aim of this work was to investigate monthly, for one year the seasonality effect on the physicochemical properties (dry weight, flavonoids contents, $\mathrm{pH}$ and antioxidant activity) of ethanolic extract (EAP) of propolis produced by three different techniques (intelligent propolis collector, plastic screen or scraping) fifteen colonies of africanized bees. No differences $(p>0.05)$ in the physicochemical properties due to the technique of propolis production and seasonality were observed.

\section{INTRODUÇÃO}

A própolis tem sido utilizada no combate a diversas patologias, sendo amplamente utilizada como antibacteriana, antiviral, antitumoral, antifúngica, antioxidante e imunomoduladora, apresentando muitas

\section{AdDitional KeYWORDS}

Apis mellifera. Africanized bees.

outras atividades biológicas (Dobrowolski et al., 1991; Amoros et al., 1992; Sforcin et al., 2000; Castro, 2001; Fernandes Jr. et al., 2005; Gonsales et al., 2005a; Orsi et al., 2005; Orsi et al., 2006).

Entretanto, diversos fatores podem interferir na qualidade da própolis, como sazonalidade e tipo de coletor utilizado (Lima, 2006). No Brasil, para assegurar a qualidade do produto, utilizam-se as normas do Regulamento Técnico de Identidade e Qualidade da Própolis (MAPA, 2001), para o extrato alcoólico de própolis: extrato seco $(>11 \% \mathrm{~m} / \mathrm{v})$, compostos fenólicos $(>0,50 \%$ $\mathrm{m} / \mathrm{m})$, flavonóides $(>0,25 \% \mathrm{~m} / \mathrm{m})$, atividade antioxidante ( $<22$ segundos), entre outros.

Considerando-se que a procura pela própolis tem crescido nos últimos anos, principalmente pelo interesse da população para os chamados produtos naturais, o levantamento de dados que contribuam para o conhecimento de fatores que possam interferir com a qualidade do produto, são de suma importância.

Diante do exposto, o objetivo do presente trabalho foi avaliar o efeito da sazonalidade sobre algumas características físico-químicas (extrato seco, flavonóides totais, $\mathrm{pH}$ e atividade de oxidação) dos extratos alcoólicos (EAP) da própolis obtida por diferentes técnicas de produção (coletor 
de própolis inteligente, tela plástica e raspagem).

\section{MATERIALE MÉTODOS}

As amostras de própolis foram produzidas no apiário da Área de Produção de Apicultura da fazenda Experimental Lageado, UNESP, Campus de Botucatu, com as seguintes coordenadas geográficas: $22^{\circ} 49^{\prime}$ de latitude Sul e $48^{\circ} 24^{\prime}$ de longitude Oeste e altitude média de 623 metros.

Foram utilizadas quinze colméias de abelhas Apis mellifera africanizadas, alojadas em colméias padrão Langstroth, pintadas externamente, distribuídas ao acaso e manejadas apenas para a produção de própolis, sendo que no período de chuvas foi necessária a realização de alimentação artificial (água e açúcar na proporção de 1: 1). Antes do início do experimento as colônias foram homogeneizadas em relação às áreas de cria e de alimento (pólen e mel).

Foram selecionadas, ao acaso, cinco colméias para cada técnica de produção utilizada (coletor de própolis inteligente, tela plástica e raspagem). A produção de própolis foi avaliada no período de maio de 2005 a abril de 2006. Mensalmente, os coletores foram remanejados entre as colméias do apiário, por meio de sorteio casualizado.

As variáveis climáticas, no período de estudo, foram fornecidas pelo Departamento de Ciências Naturais, Faculdade de Ciências Agronômicas, UNESP.

Para o preparo dos extratos alcoólicos de própolis (EAP), toda a própolis produzida mensalmente, pela mesma técnica de produção, foi misturada e mantida em freezer. Após congelada, a própolis foi triturada e os EAP foram preparados na proporção de $30 \%$ (em álcool etílico $70 \%$ ). As soluções permaneceram ao abrigo da luz, sob agitação freqüente, durante sete dias. Decorrido este período, as soluções foram filtradas e os EAP obtidos para as análises físico-químicas (Orsi et al., 2000).
As análises físico-químicas foram realizadas da Área de Produção de Apicultura do Departamento de Produção Animal da Faculdade de Medicina Veterinária e Zootecnia, UNESP.

$\mathrm{O}$ extrato seco foi determinado segundo metodologia descrita em Cunha et al. (2004). Para isto, as amostras de EAP foram mantidas sob refrigeração durante 24 horas, colocadas em béquer previamente pesado e mantidas em estufa a $105^{\circ} \mathrm{C}$, durante 2 horas, sendo em seguida determinado o teor de extrato seco.

O teor de flavonóides em quercetina foi determinado por ensaio espectrofotométrico a $425 \mathrm{~nm}$, segundo metodologia descrita por Popova et al. (2003), utilizando-se cloreto de alumínio $\left(\mathrm{AlCl}_{3}\right)$ em metanol absoluto. Para o preparo do padrão, utilizou-se quercetina em diferentes concentrações.

Para a determinação do $\mathrm{pH}$ do EAP, foi utilizado um pHmêtro digital modelo Tecnopon mPA 210. Para isto, $50 \mathrm{ml}$ do EAP são colocados em béquer e levados em contato com o leitor do aparelho. $\mathrm{O}$ pH foi registrado após estabilização. Para padronização do pHmêtro são realizadas leituras dos tampões com $\mathrm{pH}$ 4,0 e 7,0, conforme estabelecido na Farmacopéia Brasileira (1998).

Foi determinada a atividade de oxidação segundo metodologia descrita na Farmacopéia Brasileira (1998), utilizando-se permanganato de potássio $(\mathrm{KMnO} 4)$ como agente oxidante. O tempo de reação foi determinado com o auxílio de um cronômetro.

Os resultados foram comparados por ANOVA, seguida do teste de Tukey para verificar diferenças entre as médias. Foi considerado como estatisticamente diferentes quando $\mathrm{p}<0,05$ (Zar, 1996).

\section{RESULTADOSEDISCUSSÃO}

As variáveis climáticas analisadas, durante o período experimental, não apresentaram diferenças estatísticas significativas entre as estações do ano, com tempera- 


\section{QUALIDADEFÍSICO-QUÍMICADAPRÓPOLIS}

Tabela I . Extrato seco (\%), flavonóides totais (\%), pH e atividade de oxidação (AO, segundos) dos extratos alcoólicos de própolis produzidos por três diferentes técnicas de produção (CPI, tela plástica e raspagem). (Dry weight (\%), flavonoid contents (\%), $\mathrm{pH}$ and antioxidant activity (AO, seconds) of ethanolic extract of propolis produced by three different methods of production (intelligent propolis collector, plastic screen or scraping)).

\begin{tabular}{lccc}
\hline & CPI & Tela & Raspagem \\
\hline Extrato seco & $11,50 \pm 1,3$ & $11,73 \pm 2,2$ & $11,87 \pm 1,8$ \\
Flavonóides & $1,19 \pm 1,87$ & $0,30 \pm 0,12$ & $0,42 \pm 0,04$ \\
pH & $4,87 \pm 0,3$ & $4,90 \pm 0,3$ & $4,93 \pm 0,3$ \\
AO & $19,0 \pm 2,0$ & $19,0 \pm 3,0$ & $17,0 \pm 3,0$ \\
\hline
\end{tabular}

tura média de $19,8 \pm 1,6^{\circ} \mathrm{C}$, pluviometria de $3,7 \pm 2,5 \mathrm{~mm}$, umidade relativa de $53,4 \pm 4,1 \%$, insolação de $6,6 \pm 1,3$ horas e velocidade do vento de $90,6 \pm 19,9 \mathrm{~km} / \mathrm{dia}$.

As caracteristicas médias dos extratos alcoólicos da própolis, estão apresentados na tabela I e tabela II encontram-se em função da sazonalidade.

Com relação ao teor de extrato seco do EAP, verifica-se que não houve diferença significativa entre a própolis produzida pela técnica do CPI, tela plástica e raspagem (tabela I). Avaliando-se o efeito da sazonalidade sobre o teor de extrato seco (\%) presente nos EAPs, observa-se que não houve diferença significativa entre as estações do ano e os métodos de produção de própolis testados. Entretanto, pode-se observar que a própolis produzida no verão tende a apresentar maior porcentagem de extrato seco em comparação com as demais estações do ano, independente da técnica de produção utilizada (CPI, tela ou raspagem) (tabela II).

Verifica-se (tabela II) que o EAP produzido com a própolis de tela plástica e raspagem, no período do inverno, apresentou teor de extrato seco abaixo do valor mínimo (11\%) permitido pela legislação do Brasil(MAPA, 2001) (tabela II).
Lima (2006) cita que a produção de própolis deve ser evitada pelo apicultor no período do inverno, no sentido de poder prejudicar o enxame, apresentar perdas consideráveis de produção e menor qualidade do produto.

Park et al. (2000) encontraram valores na faixa de $54,0 \%$ e $65,0 \%$ para amostras provenientes da região Sudeste do Brasil e, Sato (2003) obteve valores de extrato seco variando de $1,36 \%$ em uma amostra de própolis do estado do Paraná até 95,29\% em uma amostra do estado de São Paulo. Gonsales et al. (2005b) encontraram valores de extrato

Tabela II. Extrato seco (\%), flavonóides totais (\%), pH e atividade de oxidação (segundos) dos extratos alcoólicos de própolis produzidos por diferentes técnicas de coleta (CPI, tela plástica ou raspa), em função das estações do ano. (Dry weight (\%), flavonoid contents (\%), $\mathrm{pH}$ and antioxidant activity ( $\mathrm{AO}$, seconds) of ethanolic extract of propolis produced by three different methods (intelligent propolis collector, plastic screen or scraping) in function of seasonality).

\begin{tabular}{lccc}
\hline & CPI & Tela & Raspagem \\
\hline Extrato seco & & & \\
Primavera & $12,5 \pm 0,5$ & $12,8 \pm 2,8$ & $11,4 \pm 2,1$ \\
Verão & $15,7 \pm 9,1$ & $17,1 \pm 10,0$ & $17,3 \pm 8,1$ \\
Outono & $11,8 \pm 0,4$ & $11,7 \pm 2,4$ & $11,2 \pm 2,9$ \\
Inverno & $11,2 \pm 1,9$ & $9,6 \pm 0,1$ & $10,8 \pm 1,2$ \\
Flavonóides totais & & \\
Primavera & $0,5 \pm 0,0$ & $0,4 \pm 0,1$ & $0,5 \pm 0,1$ \\
Verão & $0,4 \pm 0,1$ & $0,3 \pm 0,3$ & $0,4 \pm 0,1$ \\
Outono & $1,7 \pm 2,4$ & $0,3 \pm 0,2$ & $0,4 \pm 0,0$ \\
Inverno & $0,4 \pm 0,1$ & $0,4 \pm 0,0$ & $0,4 \pm 0,0$ \\
pH & & & \\
Primavera & $4,5 \pm 0,1$ & $4,6 \pm 0,1$ & $4,7 \pm 0,1$ \\
Verão & $4,7 \pm 0,1$ & $4,6 \pm 0,0$ & $4,7 \pm 0,0$ \\
Outono & $5,0 \pm 0,2$ & $5,1 \pm 0,1$ & $5,1 \pm 0,2$ \\
Inverno & $5,2 \pm 0,1$ & $5,2 \pm 0,0$ & $5,2 \pm 0,1$ \\
Atividade de oxidação & & \\
Primavera & $14,7 \pm 5,5$ & $19,0 \pm 1,0$ & $16,7 \pm 2,1$ \\
Verão & $15,3 \pm 4,7$ & $16,0 \pm 2,6$ & $14,3 \pm 6,0$ \\
Outono & $19,0 \pm 1,0$ & $16,7 \pm 3,5$ & $14,3 \pm 5,0$ \\
Inverno & $19,3 \pm 2,1$ & $18,7 \pm 3,2$ & $17,7 \pm 4,0$ \\
\hline
\end{tabular}


seco, para amostras de própolis do estado de São Paulo, variando entre $8,05 \%$ a $16,87 \%$.

Com relação ao teor de flavonóides totais (\%) presente no EAP das própolis obtidas por CPI, tela plástica e raspagem, no período estudado, não se observou diferença significativa entre eles (tabela I), embora o CPI tenha apresentado maior porcentagem de flavonóides $(1,17 \pm 1,87 \%)$, em comparação com a tela plástica $(0,30 \pm 0,12 \%)$ e raspagem $(0,42 \pm 0,04 \%)$. Observa-se que não houve diferença significativa entre as estações do ano e o método de produção de própolis (tabela II).

Segundo o MAPA (2001), os valores mínimos para flavonóides totais no EAP são de $0,25 \% \mathrm{~m} / \mathrm{m}$. Desta forma, pode-se verificar que todas as amostras de EAP encontram-se dentro dos valores estabelecidos na legislação, sugerindo que a sazonalidade e a técnica de produção utilizada não interferiram com esta característica físicoquímica.

Massuda (2003) obteve valores de flavonóides para amostras de extrato alcoólico de própolis na faixa de $0,53 \%$ a $1,49 \%$ e, Sato (2003) observou variação de $0,0 \%$ a $7,04 \%$ em amostras de própolis de diferentes regiões brasileiras. Da mesma forma, Marcucci et al. (1998) encontraram valores baixos de flavonóides em amostras de própolis brasileiras $(0,83 \%$ e $0,84 \%$, respectivamente). Também Thomás-Barberán et al. (1993) observaram baixos valores de flavonóides em amostras de própolis da Venezuela. Kumazawa et al. (2004) encontraram teores de flavonóides em amostras de própolis do Brasil de 0,05\%. Silva et al. (2006) encontraram valores de flavonóides totais 0,19 a $0,38 \%$ em amostras de própolis do Estado da Paraíba. Sousa et al. (2007) verificaram o teor de flavonóides totais em amostras de própolis provenientes do Estado de São Paulo (região de Franca) e Minas Gerais (região de Passo). Os autores encontraram valores de $0,38 \pm 0,06 \%$ para São Paulo e entre 0,12 a 2,11\% para a própolis de Minas Gerais.
Por outro lado, Kujumgiev et al. (1999) encontrou altos teores de flavonóides (42\%) na própolis da Bulgária. Estes resultados estão de acordo com Bracho et al. (1996) e Gonzáles e Bernal (1997), afirmaram que a própolis produzida nos trópicos é pobre em flavonóides.

A composição química da própolis depende da vegetação disponível ao redor do apiário para coleta de resina pelas abelhas (Koo e Park, 1997). Devido às diferenças geográficas, amostras de própolis provenientes da Europa contêm maiores teores de flavonóides e ésteres de ácidos fenólicos (Bankova et al., 2000). Diferentemente, os maiores componentes das própolis brasileiras são terpenóides e derivados prenilados do ácido p-cumárico (Marcucci e Bankova, 1999).

Não se verificou diferença estatística para o $\mathrm{pH}$ e atividade de oxidação das amostras de EAP da própolis proveniente dos diferentes métodos de produção (CPI, tela plástica e raspagem), no período estudado (tabela I) nem entre as estações do ano e o método de produção de própolis (tabela II).

Sato (2003) encontrou valores de $\mathrm{pH}$ para amostras de EAP variando de 3,0 a 5,7, demonstrando que o $\mathrm{pH}$ do extrato de própolis tende a ser ligeiramente ácido. Gonsales et al. (2005b) encontraram valores de $\mathrm{pH}$ para EAP variando de 4,0 a 6,0.

Pode-se observar que todas as amostras de EAP encontram-se dentro dos limites estabelecidos (tempo máximo 22 segundos) pela legislação (MAPA, 2001).

Maldonado (2000) encontrou para a própolis Argentina valores de atividade antioxidante variando entre 1,6 segundos a 120,0 segundos. Garcia et al. (2000) analisaram amostras de própolis coletadas no Estado do Paraná, no período do inverno e verão. Estes autores encontraram teores de flavonóides variando de $0,27 \%$ a $0,38 \%$ para a estação do inverno e de $0,19 \%$ a $0,52 \%$ para o verão.

Gonsales etal.(2005b) encontraram, para 


\section{QUALIDADEFIISICO-QUÍMICADAPRÓPOLIS}

amostras de própolis do Estado de São Paulo, propriedade antioxidante variando de 5 segundos a 252 segundos. Silva et al. (2006) encontraram valores de flavonóides variando de $0,19 \%$ a $0,52 \%$ para amostras de própolis produzidas no Estado da Paraíba.

\section{CONCLUSÕES}

De acordo com os resultados obtidos pode-se concluir que as propriedades físi-

\section{BIBLIOGRAFIA}

Amoros, M., Sauvager, F., Girre, L. and Cormier, M. 1992. In vitro antiviral activity of propolis. Apidologie, 23: 231-3.

Bankova, V.S., Castro, S.L. and Marcucci, M.C. 2000. Propolis: recent advances and plant origin. Apidologie. 31: 3-15

Bracho, J., Rosado, A. y Pino, J. 1996. Estudio de la composición química del propóleos cubano mediante cromatografía de gases. Espectrofotometría de masas. En: Simposio de Propóleos y III de Apiterapia, 4. 1996. La Habana, Cuba. Memoria...La Habana. 1996. 45 pp.

Castro, S.L. 2001. Propolis: biological and pharmacological activities. Therapeutic uses of this bee-product. ARBS, 3: 49-83.

Cunha, I.B., Sawaya, A.C.H.F, Caetano, F.M., Shimizu, M.T., Marcucci, M.C., Drezz, F.T., Povia, G.S. and Carvalho, P.O. 2004. Factors that influence the yield and composition of Brazilian propolis extracts. J. Braz. Chem. Soc., 15: 96470.

Dobrowolski, J.W., Vohora, S.B., Sharma, K., Shah, S.A., Naqvi, S. and Dandiyz, P.C. 1991 Antibacterial, antifungal, antiamoebic, antiinflamatory and antipyretic studies on propolis bee products. J. Ethnopharmacol., 35: 77-82.

Farmacopéia brasileira. 1998. Método modificado. $4^{\circ}$ Edição. Atheneu. São Paulo. 988 pp.

Fernandes Jr., A., Balestrin, E.C., Betoni, J.E.C., Orsi, R.O., Cunha, M.L.R. and Montelli, A.C 2005. Propolis: anti-Staphylococcus aureus activity and synergism with antimicrobial drugs Memórias do Instituto Oswaldo Cruz, 100: 563566.

Garcia, J., Mommensohn, L.G. e Moura, L.P.P. 2000. Produção de própolis em colônias de Apis co-químicas analisadas, para os extratos alcoólicos de própolis, não foram influenciadas pelo tipo de coletor utilizado para a produção de própolis (coletor de própolis inteligente, tela plástica e raspagem) e pela sazonalidade.

\section{AGRADECIMENTOS}

À Fundação de Amparo à Pesquisa do Estado de São Paulo - FAPESP.

mellifera pelas técnicas convencional de raspagem e coletor de própolis inteligente. Anuário da Universidade Estadual de Maringá. Maringá, Paraná. p. 3.

Gonsales, G.Z., Orsi, R.O., Funari, S.R.C. and Fernandes Jr, A. 2005a. Antibacterial activity of propolis collected in different regions of Brazil. J. Venom. Animal Tox. Incl. Tropical Dis., 12: 276-84.

Gonsales, G.Z., Orsi, R.O., Rodrigues, P. e Funari, S.R.C. 2005b. Análises físico-químicas de extrato alcoólico de própolis. B. Indústr. Anim., Nova Odessa, 62: 215-9.

Gonzáles, A.R. y Bernal, R. 1997. Própoleos: Un camino hacia la salud. Ed. Pablo de la Torriente. La Habana, Cuba. 132 pp.

Koo, M.H. and Park, Y.K. 1997. Investigation of flavonoid aglycones in propolis collected by two different varieties of bees in the same region. Biosci. Biotech. Bioch., 61: 367-369.

Kujumgiev, A., Tsvetkova, I., Serkedjieva, Y.U., Bankova, V., Christov, R. and Popov, S. 1999. Antibacterial, antifungal and antiviral activity of propolis of different geographic origin. J. Enthnopharmacol., 64: 235-40.

Kumazawa, S., Hamasak, T. and Nakayama, T. 2004. Antioxidant activity of propolis of various geographic origins. Food Chem., 84: 329-39.

Lima, M.G. 2006. A produção de própolis no Brasil. $1^{\circ}$ edição. São Sebastião Editora e Gráfica Ltda: São João da Boa Vista. São Paulo. 120 pp.

Maldonado, L. 2000. Perfil de los propóleos argentinos. Em: Congreso Internacional de Propóleos. Memoria. Buenos Aires. Argentina. pp. 11-17.

MAPA. 2001. Ministério de Agricultura e do Abastecimento. Instrução normativa Nº 3, de 19 


\section{SOUZA, INOUE, GOMES, FUNARI E ORSI}

de janeiro de 2001. Diário Oficial da União, Brasília, D.F. 23 de jan 2001, Seção 1. pp. 1823. http://www.extranet.agricultura.com.br (10/09/08).

Marcucci, M., Rodriguez, J. and Ferreres, F. 1998. Chemical composition of Brazilian propolis from São Paulo State. Zeitschung Naturfung, 53: 117-119.

Marcucci, M.C. and Bankova, V.S. 1999. Chemical composition, plant origin and biological activity of Brazilian propolis. Curr. Topics Phytochemistry, 2: 115-123.

Massuda, K.F. 2003. Parâmetros físico-químicos e atividade biológica da própolis submetida a diferentes tipos de extração. Monografia de conclusão de curso. Universidade Estadual Paulista. Rio Claro. 54 pp.

Orsi, R.O., Funari, S.R.C., Soares, A.M.V.C., Calvi, S.A., Oliveira, S.L., Sforcin, J.M. and Bankova, V. 2000. Immunomodulatory action of propolis on macrophage activation. J. Venom. Animal Tox., 6: 205-219.

Orsi, R.O., Sforcin, J.M., Funari, S.R.C. and Bankova, V. 2005. Effects of propolis from Brazil and Bulgaria on bactericidal activity of macrophages against Salmonella typhimurium. Int. J. Immunopharmaco., 5: 359-368.

Orsi, R.O. Sforcin, J.M., Funari, S.R.C., Fernandes Jr., A. and Bankova, V. 2006. Synergistic effect of propolis and antibiotics on the Salmonella thypi. Braz. J. Microbiol., 37: 108-112.

Park, Y.K, Ikegaki, M. e Alencar, S.M. 2000. Classificação das própolis brasileiras a partir de suas características físico-químicas e propriedades biológicas. Mensagem doce, 58: 2-7.

Popova, M., Silici, S., Kaftanoglu, O. and Bankova, V. 2003. Antibacterial activity if Turkish propolis and its qualitative and quantitative chemical composition. Phytomedicine, 12: 221-228.

Sato, P.M. 2003. Inter-relações das características físicas, químicas e biológicas de própolis das regiões sul e sudeste do Brasil. Monografia de conclusão de curso. Universidade Estadual Paulista. Rio Claro. 49 pp.

Sforcin, J.M., Fernandes Jr., A. and Lopes, C.A.M. 2000. Seasonal effect on Brazilian propolis antibacterial activity. J. Ethnopharmacol., 73: 243-249.

Silva, R.A., Rodrigues, A.E. e Ribeiro, M.C.M. 2006. Características físico-químicas e atividade antimicrobiana de extratos de própolis da Paraíba, Brasil. Ciência Rural, 36: 1842-1848. Sousa, P.B., Niege, A.J.C., Furtado, R.J., Soares, A.E.E. e Bastos, J.K. 2007. Perfis físico-químico e cromatográfico de amostras de própolis produzidas nas microrregiões de Franca (SP) e Passos (MG), Brasil. Braz. J. Pharmacognosy, 17: 85-93.

Thomás-Barberán, F.A., Garcia-Viguera, C., VitOlivier, P., Ferreres, F. and Tomas-Llorente, F. 1993. Phytochemical evidence for the botanical origin of tropical propolis from Venezuela. Phytochemistry, 34: 191-196.

Zar, J.H. 1996. Bioestatistical analysis. Pretince Hall. New Jersey.

Archivos de zootecnia vol. 59, núm. 228, p. 576. 